\title{
COUPON COLLECTOR'S PROBLEM WITH UNLIKE PROBABILITIES
}

\author{
TOSHIO NAKATA
}

Abstract. In this note we study the coupon collector's problem with unlike probabilities using majorization and a Schur concave function.

Mathematics subject classification (2010): 60C05.

Keywords and phrases: Coupon collector's problem, majorization, Schur concave function.

\section{REFERENCES}

[1] W. FelLeR, An Introduction to Probability Theory and Its Applications, vol. I, 3rd ed., Wiley, New York, 1968.

[2] P. Flajolet, D. Gardy and L. Thimonier, Birthday paradox, coupon collectors, caching algorithms and self-organizing search, Discr. Appl. Math. 39, (1992), 207-229.

[3] P. Flajolet And R. Sedgewick, Analytic Combinatorics, Cambridge University Press, 2008.

[4] K. Johg-Dev and F. Proschan, Birthday Problem with Unlike Probabilities, Amer. Math. Monthly, 99, (1992), 10-12.

[5] T. Lindvall, Lectures on the coupling method, Dover Publications, Inc., Mineola, NY, 2002.

[6] A. Marshall And I. Olkin, Inequalities: Theory of majorization and its applications, Academic Press, New York-London, 1979.

[7] H. von Schelling Coupon collecting for unequal probabilities, Amer. Math. Monthly, 61, (1954), 306-311.

[8] J. Steele, The Cauchy-Schwarz Master Class: An Introduction to the Art of Mathematical Inequalities, Cambridge UP, 2004. 